\title{
Bidirectional mm-Wave ARoF Fronthaul over Multicore Fiber for $5 G$ and Beyond
}

\section{Citation for published version (APA):}

Perez Santacruz, J., Nazarikov, G., Rommel, S., Jurado-Navas, A., \& Tafur Monroy, I. (2021). Bidirectional mmWave ARoF Fronthaul over Multicore Fiber for 5G and Beyond. In 2021 International Topical Meeting on Microwave Photonics, MWP 2021 [9639425] Institute of Electrical and Electronics Engineers. https://doi.org/10.1109/MWP53341.2021.9639425

\section{Document license:}

CC BY

DOI:

10.1109/MWP53341.2021.9639425

Document status and date:

Published: 14/12/2021

\section{Document Version:}

Accepted manuscript including changes made at the peer-review stage

\section{Please check the document version of this publication:}

- A submitted manuscript is the version of the article upon submission and before peer-review. There can be important differences between the submitted version and the official published version of record. People interested in the research are advised to contact the author for the final version of the publication, or visit the $\mathrm{DOI}$ to the publisher's website.

- The final author version and the galley proof are versions of the publication after peer review.

- The final published version features the final layout of the paper including the volume, issue and page numbers.

Link to publication

\section{General rights}

Copyright and moral rights for the publications made accessible in the public portal are retained by the authors and/or other copyright owners and it is a condition of accessing publications that users recognise and abide by the legal requirements associated with these rights.

- Users may download and print one copy of any publication from the public portal for the purpose of private study or research.

- You may not further distribute the material or use it for any profit-making activity or commercial gain

- You may freely distribute the URL identifying the publication in the public portal.

If the publication is distributed under the terms of Article 25fa of the Dutch Copyright Act, indicated by the "Taverne" license above, please follow below link for the End User Agreement:

www.tue.nl/taverne

Take down policy

If you believe that this document breaches copyright please contact us at:

openaccess@tue.nl

providing details and we will investigate your claim. 


\section{Bidirectional mm-Wave ARoF Fronthaul over Multicore Fiber for 5G and Beyond}

\author{
Javier Pérez Santacruz \\ Institute for Photonic Integration \\ Eindhoven University of Technology \\ Eindhoven, The Netherlands \\ j.perez.santacruz@tue.nl
}

\author{
Gleb Nazarikov \\ Institute for Photonic Integration \\ Eindhoven University of Technology \\ Eindhoven, The Netherlands \\ g.i.nazarikov@tue.nl
}

\author{
Simon Rommel \\ Institute for Photonic Integration \\ Eindhoven University of Technology \\ Eindhoven, The Netherlands \\ s.rommel@tue.nl
}

\author{
Antonio Jurado-Navas \\ Department of Communications Engineering \\ University of Málaga \\ Málaga, Spain \\ navas@ic.uma.es
}

\author{
Idelfonso Tafur Monroy \\ Institute for Photonic Integration \\ Eindhoven University of Technology \\ Eindhoven, The Netherlands \\ i.tafur.monroy@tue.nl
}

\begin{abstract}
In this work we present, analyze, and demonstrate an efficient bidirectional ARoF system for K-band 5G fronthaul based on multicore fiber. As the 5G standard establishes, the experimental testbed is configured regarding the time division duplex scheduling and tested by transmitting OFDM signals. Furthermore, the configuration of the setup enables the reusability of several components for both directions, allowing the reduction of the power consumption, complexity, and cost of the system. The bidirectional testbed is experimentally evaluated under different bandwidth configurations and power levels, achieving a maximum throughput of $4 \mathrm{Gbit} / \mathrm{s}$ over $9 \mathrm{~m}$ of wireless link. The experimental results prove and validate the proposed bidirectional ARoF scheme as a promising solution for the future mm-Wave 5G fronthaul.
\end{abstract}

Index Terms-5G; Analog radio-over-fiber; Fronthaul; OFDM; Bidirectional; mm-Wave; Multicore fiber.

\section{INTRODUCTION}

The fifth generation $(5 \mathrm{G})$ of mobile networks aims to fulfill the highly demanding data requirements in terms of bit rate, latency, and energy efficiency, among others [1], [2]. The millimeter-wave (mm-Wave) spectrum provides large available bandwidths compared to the saturated frequency bands (under $6 \mathrm{GHz}$ ) employed in the current mobile networks and can thus support substantially larger data rates. However, since the free-space path losses (FSPL) increases as the frequency does, the number of mm-Wave cells will be much larger than the current number of sub- $6 \mathrm{GHz}$ cells to cover the same area. Moreover, centralized radio access network (C-RAN) is a preferred option in terms of flexibility, latency, and energy consumption.

To avoid the bottleneck that the already implemented 5G technologies (common public radio interface (CPRI) or enhanced CPRI (eCPRI)) cause in the fronthaul, analog radioover-fiber (ARoF) is an excellent solution for the transport of high-bandwidth mm-Wave signals due to their attractive benefits such as high spectral efficiency, large bandwidth, and low complexity [3]. ARoF fronthaul over optical multiplexing solutions, such as dense wavelength-division multiplexing (DWDM) and space-division multiplexing (SDM), offers a highly scalable architecture that can support the enormous number of future $5 \mathrm{G} \mathrm{mm}$-Wave cells. Furthermore, the scalability of this solution enables centralized optical beamforming that reduces the complexity in the remote antenna unit (RAU) [3]. Moreover, employing optical SDM enhances the communication performance for bidirectional links rather than utilizing single optical fibers [4].

The works realized in [5] and [6] experimental demonstrated a bidirectional ARoF system under the Long Term Evolution (LTE) standardization. However, there is still a investigation gap in bidirectional ARoF systems over SDM oriented to $5 \mathrm{G}$ fronthaul. For that reason, this paper presents and demonstrates a novel mm-Wave ARoF scheme that allows an efficient bidirectional communication for $5 \mathrm{G}$ signals. In addition, the configuration of the experimental setup permits a K-band wireless link at $26 \mathrm{GHz}$ (n258 band) by using time division duplexing (TDD), as defined for mm-Wave in the 5G standards [7]. Orthogonal frequency-division multiplexing (OFDM) signals are sent through the setup with different bandwidths $(250 \mathrm{MHz}$ to $1000 \mathrm{MHz})$ and a subcarrier spacing value of $240 \mathrm{kHz}$. Furthermore, several key aspects of the experimental configuration are discussed to optimize the final performance. The experimental results show bit error rate (BER) under the forward error correction (FEC) thresholds proving that the proposed scheme is a suitable solution for the future mm-Wave $5 \mathrm{G}$ fronthaul.

\section{ScAlable ARChitecture of ARoF For MM-WAVE 5G FRONTHAUL}

Fig. 1 shows the general architecture of the ARoF fronthaul to support mm-Wave signal transport from the central office (CO) to the 5G RAUs or cells. The CO performs all the signal processing, management, and monitoring, reducing the complexity in the RAUs. First, the corresponding OFDM 


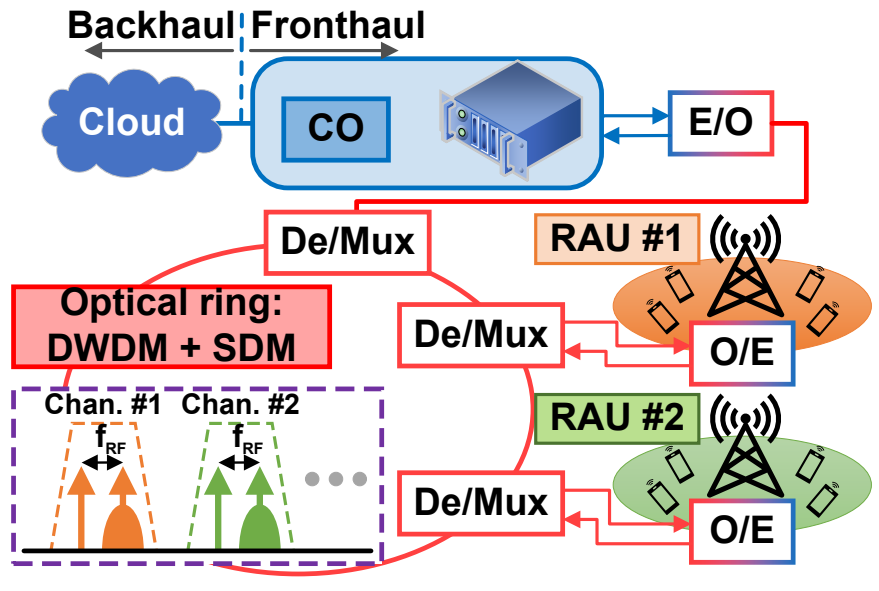

Fig. 1. Overview of the ARoF fronthaul architecture for $5 \mathrm{G} \mathrm{mm-Wave} \mathrm{cells.}$ CO: central office; Mux: multiplexer.

modulated signals for each RAU are generated in the CO. Next, these modulated signals are up-converted to the $\mathrm{mm}$ Wave domain and transported through the optical fibre. The spectrum of the transported optical signals are represented in Fig. 1. The optical mm-Wave up-conversion can be realized in different manners, with launch power and phase noise being two of the key parameters that determine the communication stability of this process [8], [9].

After the optical fiber ring, the transported optical signals corresponding to each RAU can be multiplexed into independent DWDM channels (see graph of the spectrum inserted in Fig. 1). Later, a DWDM demultiplexer process is carried out to select the desired optical signal. By converting the selected optical signal into the electrical domain, a mm-Wave signal is obtained and can be directly used in the RAU without employing electrical up-conversion. Hence, the hardware requirement on each RAU is highly reduced, allowing the viability of deploying the enormous expected number of mm-Wave cells in the future $5 \mathrm{G}$ fronthaul. In the demultiplexing blocks, SDM can be realized to achieve bidirectional communication and optical beamforming monitored from the $\mathrm{CO}$ [3]. The uplink procedure follows a similar strategy in the opposite direction. In this way, the bidirectional communication of a large number of mm-Wave cells can be provided in a very scalable manner.

\section{EXPERIMENTAL SETUP}

The experimental schematic of the proposed bidirectional ARoF system for the mm-Wave ARoF fronthaul is shown in Fig. 2. First, in the downlink direction, an optical carrier is generated at $1550 \mathrm{~nm}$ in an external cavity laser (ECL). Next, two optical tones with a separation of $23 \mathrm{GHz}$ are produced by using a Mach-Zehnder modulator (MZM), biased in the null point. These two optical tones are boosted with an erbiumdoped fiber amplifier (EDFA). Then, the boosted optical tones are modulated with the data signal by employing an arbitrary waveform generator (AWG) and a second MZM, biased in the quadrature point. The data signal of the downlink corresponds to an OFDM modulation with a subcarrier spacing of $240 \mathrm{kHz}$ and an intermediate frequency (IF) of $3 \mathrm{GHz}$. This signal procedure for the downlink is realized in the CO.

Then, the modulated optical tones travel through a multicore fiber $(\mathrm{MCF})$ of $10 \mathrm{~km}$ that represents the distance between the $\mathrm{CO}$ and the RAU. In the downlink part of the RAU, the optical signals beat on a photodiode (PD), generating the electrical RF carrier at $23 \mathrm{GHz}$ and two OFDM sidebands at $20 \mathrm{GHz}$ and $26 \mathrm{GHz}$. The OFDM sideband of $26 \mathrm{GHz}$ is the desired data signal for both directions of the communication in the wireless domain. Later, the obtained electrical signal is boosted and launched to a wireless link of $9 \mathrm{~m}$ by utilizing a medium power amplifier (MPA) and a horn antenna, respectively. Next, the receiver antenna of the end-user receives the transmitted signal. This received signal is amplified by a low noise amplifier (LNA) and mixed with a sinusoid of $25 \mathrm{GHz}$, moving the desired OFDM sideband to an IF of $1 \mathrm{GHz}$. Finally, the resulting electrical signal is captured with a digital phosphor oscilloscope (DPO) and processed offline.

For the uplink direction, the end-user generates an OFDM signal at $1 \mathrm{GHz}$ of IF in a second $A W G$ with the same configuration as the downlink data signal. Next, this OFDM signal is mixed with the local oscillator (LO) of $25 \mathrm{GHz}$, reusing the frequency synthesizer also employed in the downconversion of the downlink. Therefore, two OFDM sidebands are produced at $24 \mathrm{GHz}$ and $26 \mathrm{GHz}$, the $26 \mathrm{GHz}$ sideband signal being the desired. Then, the electrical signal is boosted and sent to the wireless by a second MPA and another horn antenna. In the RAU, the captured signal in the receiver antenna is amplified by a second LNA and mixed with the $23 \mathrm{GHZ}$ carrier of the downlink. It is feasible to reuse the downlink $23 \mathrm{GHz}$ carrier because a TDD communication is performed and, thus, the downlink carrier is unmodulated when it is needed for down-conversion of the uplink. Therefore, the desired OFDM sideband is moved to an IF of $3 \mathrm{GHz}$. The non-desired high frequency components of the down-converted signal are suppressed with a low-pass filter (LPF).

Later, the filtered signal is amplified and converted into the optical domain by using a third MZM and a second ECL that generates an optical carrier at $1548 \mathrm{~nm}$. This optical uplink signal is thrown to a different core of the MCF than for the downlink. Then, in the CO, the uplink optical signal is detected by a second PD, converting the signal into the electrical domain. Finally, the resulting electrical signal is amplified, sampled by a DPO, and processed offline. It is important to highlight that the reuse of RF carriers for the down and up-conversion in both direction of the communication highly reduces the hardware complexity of the system and the power consumption [10]. Moreover, the signal spectrum in some points of the schematic are shown in the bottom of Fig. 2 and some photographs of the experimental testbed are illustred in Fig. 3.

Respecting the different configurations evaluated in the setup, the tested bandwidths are $250 \mathrm{MHz}, 500 \mathrm{MHz}$, and $1000 \mathrm{MHz}$. The reason for these selected bandwidth values is because the $5 \mathrm{G}$ standard establishes wireless communication above $6 \mathrm{GHz}$ with a channel bandwidth between $100 \mathrm{MHz}$ 


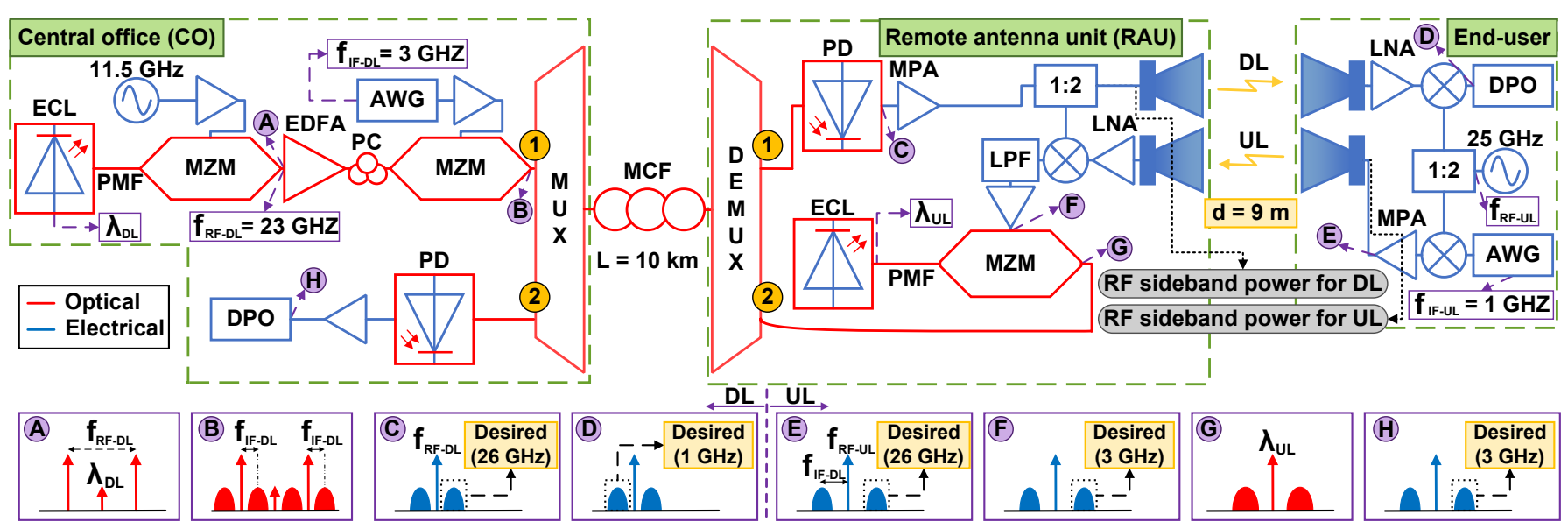

Fig. 2. Experimental testbed of the bidirectional ARoF fronthaul for $5 \mathrm{G}$ communications.

and $1 \mathrm{GHz}$ [7]. In addition, the common OFDM parameters of these selected bandwidth configurations are the following: $80 \%$ of active subcarriers, $7 \%$ cyclic prefix (CP) overhead, subcarrier spacing of $240 \mathrm{kHz}$, demodulation reference signals (DM-RS) on every every $14^{\text {th }}$ OFDM symbol or slot, and a phase tracking reference signal (PT-RS) on every $8^{\text {th }}$ resource block. Furthermore, 16-QAM and 64-QAM modulations are utilized for all the different bandwidth configurations. By employing 64-QAM modulation in the data subcarriers, the achieved throughputs are $1 \mathrm{Gbit} / \mathrm{s}, 2 \mathrm{Gbit} / \mathrm{s}$ and $4 \mathrm{Gbit} / \mathrm{s}$ for $250 \mathrm{MHz}, 500 \mathrm{MHz}$, and $1000 \mathrm{MHz}$ bandwidth configurations, respectively. The resulting throughput by using 16-QAM modulation can be easy calculated by dividing the 64-QAM throughput values by a factor of 1.5 .

In order to mitigate the deterioration of the signal due to the impairments of the experimental system, several digital signal process (DSP) blocks are carried out. These DSP processes are realized for both directions and are the next: a synchronization process by using the added preamble in the beginning of the

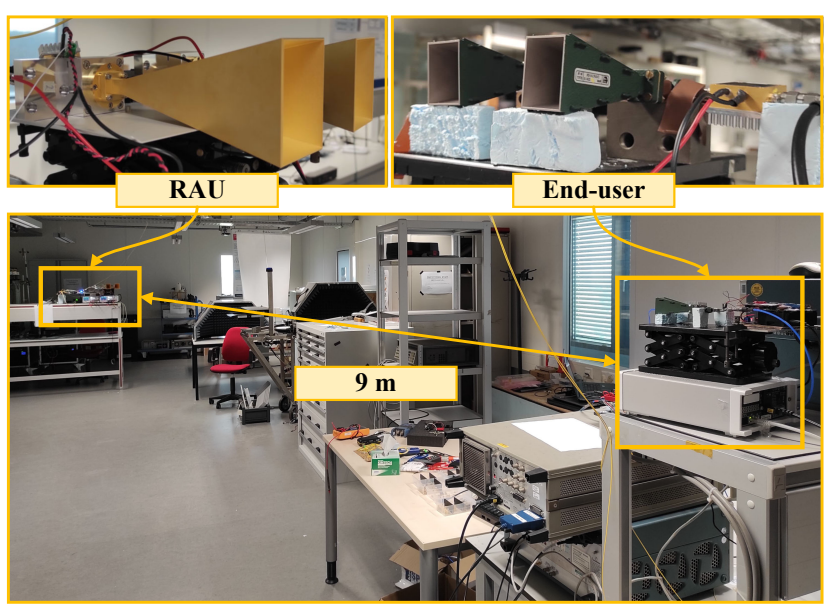

Fig. 3. Photographs of the laboratory wireless link. transmitted signal; a coarse carrier frequency offset (CFO) procedure by using the synchronization preamble; a channel equalizer by using the DM-RS signals allocated in very slot; and a linear interpolation based intercarrier interference (ICI) estimation technique (also called LI-CPE) that uses the PTRS signals and CP of every OFDM symbol to compensate the common phase error (CPE) produced by the phase noise [11].

\section{BIDIRECTIONAL TRANSMISSION RESULTS}

The experimental results are shown in Fig. 4 in terms of BER. The RF sideband power of the desired data signal at $26 \mathrm{GHz}$ is measured before the transmitter antenna for each direction (see gray labels of Fig. 2) and is utilized in the $\mathrm{x}$ axis of Fig. 4 in order to represent the BER of both direction at the same plot: uplink (continuous) and downlink (dashed). Furthermore, the aforementioned bandwidth configurations are evaluated and compared for both directions and modulation orders of 16-QAM and 64-QAM. Moreover, the 7\% and 25\% overhead $(\mathrm{OH})$ FEC thresholds are also represented in this figure. Observing Fig. 4, it can be noticed that BER is higher for larger bandwidth values since the signal-to-noise ratio (SNR) decreases as the bandwidth increases while the signal power stays the same.

Examining the results of Fig. 4, the downlink BER performs worse that the uplink results under the same power condition. The main reason of this fact is because the SNR of the uplink is larger than in the downlink. One of the main noise sources in the communication system of Fig. 2 is the EDFA that is only employed in the downlink part. Furthermore, the noise contribution of the EDFA becomes higher since no filtering process of the desired optical signal is performed before the PD. Therefore, the utilization of an optical filtering process, the usage of the EDFA, and its location in the system are keys to increase the SNR of both directions. A way to avoid the need of using the EDFA in the downlink is by performing another technique for the two-tone generation with high-power output rather than the employed external modulation method [9]. However, most of the high-power 

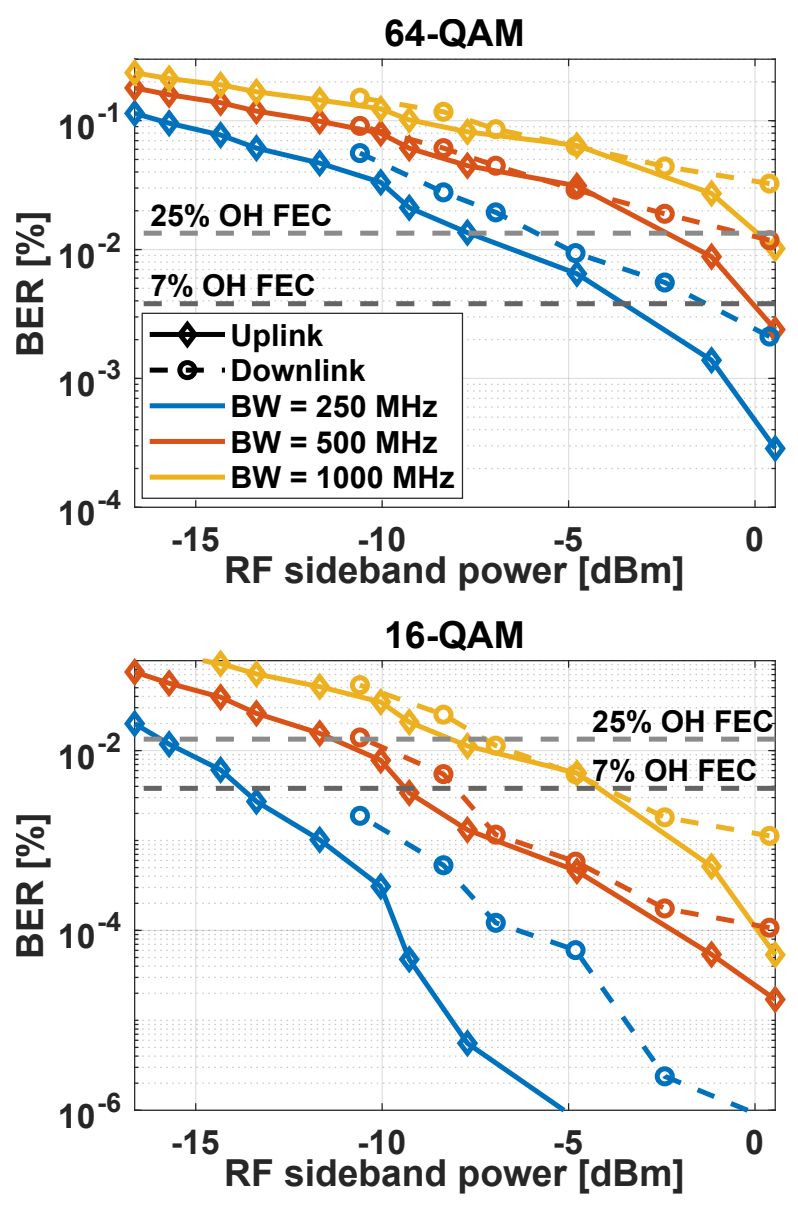

Fig. 4. BER as a function of the RF sideband power for both directions, several bandwidth configurations, and different modulation orders: 64-QAM (top) and 16-QAM (bottom).

two-tone generation techniques contains higher phase noise levels which extremely deteriorates the performance when $5 \mathrm{G}$ numerologies are employed [8], [12]. Lastly, regarding Fig. 4, it is relevant to mention that the 16-QAM BER results of all the experiment configurations at the maximum power are below the $7 \% \mathrm{OH}$ FEC threshold. The same occurs for the 64-QAM results considering the $25 \%$ OH FEC limit with the exception of the $1000 \mathrm{MHz}$ downlink result case.

\section{CONCLUSiOns}

A novel bidirectional ARoF scheme for mm-Wave 5G fronthaul has been proposed and experimentally demonstrated. The usage of ARoF over MCF allows a highly scalable bidirectional architecture for the numerous expected mm-Wave cells. The experimental testbed has been configured conforming to the $5 \mathrm{G}$ standard for different bandwidth values and the results show BER values under the FEC limits. Therefore, this work serves to highlight the viability of ARoF links for mmWave $5 \mathrm{G}$ and beyond by proposing and proving an efficient bidirectional ARoF fronthaul based on MCF.

\section{ACKNOWLEDGMENT}

This work was partially financed by the 5G STEP FWD (GA no. 722429) and blueSPACE (GA no. 762055) projects.

\section{REFERENCES}

[1] D. Konstantinou et al., "5G RAN architecture based on analog radioover-fiber fronthaul over UDWDM-PON and phased array fed reflector antennas," Optics Communications, vol. 454, p. 124464, Jan. 2020.

[2] J. P. Santacruz, S. Rommel, U. Johannsen, A. J. Navas, and I. Tafur Monroy, "Candidate Waveforms for ARoF in Beyond 5G," Appl. Sci., vol. 10, no. 11 , Jun. 2020

[3] S. Rommel et al., "Towards a Scaleable 5G Fronthaul: Analog Radioover-Fiber and Space Division Multiplexing," J. Lightwave Technol., vol. 38 , no. 19 , pp. 5412-5422, Oct. 2020.

[4] A. Kaszubowska-Anandarajah, A. Delmade, E. Martin, P. Anandarajah, L. Barry, and C. Browning, "Bidirectional fiber transmission of mmW signals using remote downconversion and wavelength reuse," in Conference on Lasers and Electro-Optics, Munich, Germany. Optical Society of America, May 2019, p. SM4G.2.

[5] P. T. Dat, A. Kanno, N. Yamamoto, and T. Kawanishi, "Full-Duplex Transmission of LTE-A Carrier Aggregation Signal Over a Bidirectional Seamless Fiber-Millimeter-Wave System," J. Lightwave Technol., vol. 34, no. 2, pp. 691-700, Jan. 2016.

[6] P. T. Dat et al., "Performance Evaluation of Full-Duplex MIMO Seamless Fiber-Wireless System in W -Band," IEEE Photon. Technol. Lett., vol. 30, no. 13, pp. 1175-1178, Jul. 2018.

[7] 3GPP, FG IMT-2020: Study on New Radio (NR) access technology. 3GPP TR 38.912, version 16.0.0, Jul. 2020.

[8] I. Degli-Eredi et al., "Millimeter-wave generation using hybrid silicon photonics," Journal of Optics, vol. 23, no. 4, p. 043001, Mar. 2021.

[9] J. P. Santacruz et al., "Experimental ARoF System Based on OPLL Mm-Wave Generation for Beyond 5G," in 2021 Opto-Electronics and Communications Conference (OECC), Jul. 2021, pp. 1-3, in press.

[10] A. Morales et al., "Bidirectional K-Band Photonic/Wireless Link for 5G Communications," in 2019 44th International Conference on Infrared, Millimeter, and Terahertz Waves (IRMMW-THz), Paris, France, Sep. 2019, pp. 1-2.

[11] Y. Ha and W. Chung, "A Feedforward Partial Phase Noise Mitigation in the Time-Domain using Cyclic Prefix for CO-OFDM Systems," Journal of the Optical Society of Korea, vol. 17, no. 6, pp. 467-470, Nov. 2013.

[12] J. P. Santacruz, S. Rommel, U. Johannsen, A. Jurado-Navas, and I. T. Monroy, "Analysis and Compensation of Phase Noise in Mm-Wave OFDM ARoF Systems for Beyond 5G," J. Lightwave Technol., vol. 39, no. 6, pp. 1602-1610, Mar. 2021. 